\title{
Zastosowanie wybranych bodźców fizykalnych podczas profesjonalnych zabiegów kosmetologicznych. Część III. Prąd niskiej częstotliwości i fale elektromagnetyczne o częstotliwości radiowej jako alternatywa inwazyjnych zabiegów z zakresu medycyny estetycznej
}

\section{The use of selected physical factors in professional cosmetology treatments. Part 3. Low-frequency current and radio-frequency electromagnetic waves as an alternative to invasive aesthetic medicine treatments}

\author{
Jolanta Wesołowska ${ }^{1}$, Iza Iwan-Ziętek ${ }^{1}$, Hanna Mosiejczuk², Ewa Kemicer-Chmielewska³, \\ Mariola Marchlewicz \\ ${ }^{1}$ Pomorski Uniwersytet Medyczny w Szczecinie, Zakład Dermatologii Estetycznej, al. Powstańców Wlkp. 72, 70-111 Szczecin \\ 2 Pomorski Uniwersytet Medyczny w Szczecinie, Zakład Rehabilitacji Medycznej i Fizjoterapii Klinicznej, ul. Żołnierska 54, 71-210 Szczecin \\ ${ }^{3}$ Pomorski Uniwersytet Medyczny w Szczecinie, Katedra i Zakład Zdrowia Publicznego, ul. Żołnierska 48, 71-210 Szczecin \\ $\triangle$ jolanta.wesolowska@pum.edu.pl
}

\section{ABSTRACT}

The use of different physical stimuli improves the effectiveness of cosmetic treatments. The development of an optimal methodology for cosmetic treatments using electrical stimulation and methods of treatments using radio-frequency electromagnetic

\section{ABSTRAKT}

Zastosowanie różnych bodźców fizykalnych wpływa na podniesienie skuteczności zabiegów kosmetycznych. Opracowanie optymalnej metodyki zabiegów kosmetycznych z użyciem elektrostymulacji i metodyki zabiegów z zastosowaniem fal waves, and the use of active substances that stimulate regeneration of collagen, elastin and hyaluronic acid can improve the skin's structure.

Keywords: electrostimulation; radio frequency.

elektromagnetycznych o częstotliwości radiowej oraz zastosowanie substancji aktywnych stymulujących regenerację kolagenu, elastyny i kwasu hialuronowego może wpłynąć na poprawę struktury skóry.

Słowa kluczowe: elektrostymulacja; fale radiowe.
Współczesna medycyna estetyczna oferuje szeroką gamę inwazyjnych zabiegów przeprowadzanych przez chirurgów plastycznych oraz lekarzy medycyny estetycznej, skutecznie wpływających na poprawę wyglądu skóry i sylwetki, a tym samym na efekt odmłodzenia [1]. Są to zabiegi zarówno z zakresu chirurgii plastycznej (liftingu) twarzy i innych obszarów ciała, jak i zabiegi z zastosowaniem różnego rodzaju substancji aktywnych oraz implantów [1,2]. Od dłuższego czasu na rynku usług estetycznych trwa dyskusja dotycząca zakresu uprawnień i dopuszczalności wykonywania przez kosmetyczki i kosmetologów zabiegów z zakresu medycyny estetycznej. 0 ile brak jest wątpliwości co do zakazu przeprowadzania zabiegów z zakresu chirurgii plastycznej przez kosmetyczki i kosmetologów, o tyle kwestia dopuszczalności wykonywania przez specjalistów tych zawodów zabiegów inwazyjnych, polegających na iniekcji i wprowadzaniu różnego rodzaju substancji i materiałów do tkanek, nadal nie jest uregulowana prawnie. Rodzi to wiele wątpliwości i emocji zarówno ze strony lobby medycznego, jak i kosmetycznego [3, 4]. W odróżnieniu od zabiegów medycyny estetycznej, których efekt jest prawie natychmiastowy, zabiegi kosmetyczne wymagają czasu, systematyczności i cierpliwości w dążeniu do osiągnięcia oczekiwanego efektu. W kosmetologii przeciwstarzeniowej zastosowanie mają różnego rodzaju substancje aktywne (indukujące syntezę kolagenu i kwasu hialuronowego), różne techniki masażu o właściwościach liftingujących oraz urządzenia kosmetyczne emitujące różne bodźce fizykalne, niewykorzystujące inwazyjnych technik medycyny estetycznej. W medycynie fizykalnej fale elektromagnetyczne o małej i wielkiej częstotliwości stosowane są w celu stymulowania komórek organizmu i poprawy ich funkcji biologicznych. Dział terapii fizykalnej wykorzystujący w procesie leczenia czy diagnostyki prąd stały, prąd małej, średniej i wielkiej częstotliwości zaliczany jest do elektroterapii. Prąd zmienny o małej częstotliwości stosowany jest do stymulacji skurczu włókien mięśniowych. Skurcz mięśni może być wywołany bezpośrednim oddziaływaniem elektrody na włókna mięśniowe lub pośrednio na nerwy ruchowe 
stymulujące mięśnie. Podczas elektrostymulacji zwykle stosowany jest prąd impulsowy niskiej częstotliwości w przedziale 10-120 Hz i różnym kształcie impulsu. W celu pobudzenia mięśni zdrowych stosowany jest impuls o kształcie prostokątnym, natomiast mięśni uszkodzonych (porażenie, niedowład) impuls trójkątny. Impulsy mogą być stosowane pojedynczo lub w seriach o odpowiednim kształcie, czyli obwiedni. W medycynie prądy małej częstotliwości stosowane są również w celu usprawnienia procesów przemiany materii, usprawnienia krążenia obwodowego, w terapii zaburzeń układu nerwowego wegetatywnego oraz w terapii przeciwbólowej [5, 6, 7]. We współczesnej kosmetologii zabiegi z zakresu elektroterapii stały się nieodłącznym elementem większości zabiegów. Stosowane są głównie podczas zabiegów galwanizacji, jonoforezy, mezoterapii bezigłowej, elektrostymulacji mięśni (zabiegi liftingujące, antycellulitowe, modelujące sylwetkę ciała) $[8,9]$. Elektrostymulacja jest głównie stosowana podczas zabiegów kosmetycznych, których celem jest uzyskanie efektu liftingu w obrębie skóry twarzy, skóry ramion, powłok brzusznych i pośladków oraz wspomaganie działania lipolitycznego - w obrębie obszarów z nadmiernie rozwiniętą tkanką tłuszczową. Jest również łączona z innymi metodami (ultradźwiękami, falami radiowymi, drenażem podciśnieniowym) podczas zabiegów antycellulitowych i zmniejszających zawartość tkanki tłuszczowej [5]. W tabeli 1 przedstawiono wybrane urządzenia kosmetyczne, w których zastosowano prąd niskiej i średniej częstotliwości.

Obecnie bardzo popularne stały się zabiegi odmładzające z zakresu elektroterapii, podczas których wykorzystywane jest pole elektromagnetyczne o częstotliwości radiowej, w nomenklaturze kosmetycznej określane jako fale radiowe [10, 11, 12]. Częstotliwość fal radiowych stosowanych podczas zabiegów kosmetycznych mieści się w zakresie od 1 MHz do 6-7 MHz. Podczas zabiegu wykorzystane jest zjawisko oddziaływania pola elektromagnetycznego generowanego prądem wysokiej częstotliwości. Zmienne pole elektryczne wywołuje drgania cząstek obdarzonych ładunkiem, czego efektem jest wytworzenie w tkankach endogennego ciepła. W zależności od rozmieszczenia elektrod w głowicy zabiegowej (aplikatorze) urządzenia generującego fale radiowe rozróżnia się głowice monopolarne lub bipolarne. Takie rozmieszczenie elektrod zdeterminowało wprowadzenie podziału urządzeń kosmetycznych i metod zabiegu na fale radiowe monopolarne i fale radiowe bipolarne (tab. 2).

TABELA 1. Charakterystyka wybranych urządzeń kosmetycznych (na podstawie materiałów informacyjnych producenta)

\begin{tabular}{|c|c|c|c|}
\hline Urządzenie & $\begin{array}{l}\text { Eco } 88 \\
\text { Certyfikat CE }\end{array}$ & $\begin{array}{l}\text { Electrostimulation slimming machine } \\
\qquad \begin{array}{c}\text { Ib-9116 } \\
\text { Certyfikat CE }\end{array}\end{array}$ & $\begin{array}{c}\text { Żelazko przeciwzmarszczkowe } \\
\text { Mid-06 } \\
\text { Certyfikat CE }\end{array}$ \\
\hline $\begin{array}{l}\text { Producent, } \\
\text { dystrybutor }\end{array}$ & Econova & Simon & Abacosun \\
\hline Elektrostymulacja & tens/ems & tens/ems & tens \\
\hline $\begin{array}{l}\text { Programy } \\
\text { zabiegowe }\end{array}$ & 6 & 9 & $\begin{array}{l}\text { mikrostymulacja tens, masaż } \\
\text { próżniowy vacum }\end{array}$ \\
\hline Program 1 & $\begin{array}{l}\text { elektropunktura } \\
\downarrow \\
\text { symulacja akupunktury }\end{array}$ & $\begin{array}{l}\text { działanie lipolityczne } \\
\text { (w powierzchownej warstwie } \\
\text { podskórnej), prąd niskiej częstotliwości }\end{array}$ & $\begin{array}{l}\text { wzmocnienie, regeneracja mięśni, } \\
\text { poprawa elastyczności skóry, } \\
\text { pobudzenie układu limfatycznego }\end{array}$ \\
\hline Program 2 & $\begin{array}{l}\text { masaż } \\
\downarrow \\
\text { symulacja masażu klasycznego }\end{array}$ & $\begin{array}{l}\text { stymulacja lipolityczna, zwiększenie } \\
\text { napięcia mięśni, prąd średniej } \\
\text { częstotliwości }\end{array}$ & $\begin{array}{l}\text { masaż próżniowy, stymulacja pracy } \\
\text { układu limfatycznego, poprawa } \\
\text { ukrwienia tkanek }\end{array}$ \\
\hline Program 3 & $\begin{array}{l}\text { młotkowanie } \\
\downarrow \\
\text { rytmiczne impulsy (uderzenia), } \\
\text { stymulacja nerwów, zwiększenie } \\
\text { wytwarzania endorfin }\end{array}$ & $\begin{array}{l}\text { głęboka stymulacja mięśni, szerokość } \\
\text { i częstotliwość impulsów większa niż } \\
\text { w programach (1 i } 2)\end{array}$ & - \\
\hline Program 4 & $\begin{array}{l}\text { ugniatanie } \\
\downarrow \\
\text { pobudzenie silnych skurczów mięśni, } \\
\text { wzmocnienie i uelastycznienie }\end{array}$ & $\begin{array}{l}\text { silne działanie modelujące, } \\
\text { przyspieszenie metabolizmu i syntezy } \\
\text { białek }\end{array}$ & - \\
\hline Program 5 & $\begin{array}{l}\text { stymulacja kompleksowa } \\
\downarrow \\
\text { kombinacja różnych częstotliwości, } \\
\text { działanie przeciwbólowe } \\
\text { i wzmacniające mięśnie }\end{array}$ & $\begin{array}{l}\text { aktywny trening mięśni, wzrost } \\
\text { objętości mięśni }\end{array}$ & - \\
\hline Program 6 & $\begin{array}{l}\text { fitness } \\
\text { silna stymulacja mięśni, ujędrnienie, } \\
\text { modelowanie sylwetki, spalanie tkanki } \\
\text { tłuszczowej }\end{array}$ & drenaż limfatyczny & - \\
\hline Program 8 & - & $\begin{array}{l}\text { tryb relaksujący, prąd średniej } \\
\text { częstotliwości, fala sinusoidalna }\end{array}$ & - \\
\hline Program 9 & - & cykliczne powtarzanie programów 1-8 & - \\
\hline
\end{tabular}


TABELA 2. Wybrane urządzenia kosmetyczne, w których zastosowano pole elektromagnetyczne o częstotliwości radiowej (na podstawie materiałów informacyjnych producenta)

\begin{tabular}{|c|c|c|}
\hline Urządzenie & Radio prequency & Radio frequency skin rejuvenation system \\
\hline Producent & Rubica beauty equipment & Hebe \\
\hline Częstotliwość & $1 \mathrm{Mhz}$ & $1 \mathrm{Mhz}$ \\
\hline Wypetnienie falii & $\begin{array}{l}\text { fala ciągła } \\
\text { fala pulsacyjna: } \\
1 \mathrm{~s}, 60 \mathrm{~ms} \text { i } 100 \mathrm{~ms}\end{array}$ & $\begin{array}{l}\text { fala ciągła } \\
\text { fala pulsacyjna: } \\
1 \mathrm{~s}, 50 \mathrm{~ms} \text { i } 100 \mathrm{~ms} \\
0,5-5 \mathrm{~Hz}\end{array}$ \\
\hline Głowice & $\begin{array}{l}6 \text { sztuk } \\
\text { stożkowa - okolice oczu } \\
\text { okrągła } \varnothing 30 \mathrm{~mm} \text { - twarz } \\
\text { okrągła } \varnothing 40 \text { i } 50 \mathrm{~mm} \text { - ramiona } \\
\text { okrągłą } \varnothing 60 \text { i } 70 \mathrm{~mm} \text { - inne obszary ciała }\end{array}$ & $\begin{array}{l}3 \text { sztuki (twarz, ciało, bruzdy) } \\
\text { działanie wzmocnione laserem biostymulującym } \\
\text { laser półprzewodnikowy } 650 \mathrm{~nm} / 3 \mathrm{mw} \text { ) }\end{array}$ \\
\hline Elektroda bierna & elektroda stalowa lub jednorazowe/samoprzylepne & - \\
\hline Funkcje/program & 6 & 7 \\
\hline Program 2 & $\begin{array}{l}\text { lifting okolicy oczu } \\
\text { czas trwania: } 10 \mathrm{~min} \\
\text { fala pulsacyjna: } 60 \mathrm{~ms} \\
\text { (bez możliwości zmiany) } \\
\text { intensywność: } 3-7 \\
2,4-3,6 \mathrm{~W} / \mathrm{cm}^{2}\end{array}$ & $\begin{array}{l}\text { lifting twarzy } \\
\text { moc: 0-42 W } \\
\text { czas trwania: } 20 \mathrm{~min} \\
\text { puls: } 4,0 \mathrm{~Hz} \\
\text { z możliwością: } 0-5,0 \mathrm{~Hz}\end{array}$ \\
\hline Program 3 & $\begin{array}{l}\text { ujędrnianie i wyszczuplanie ramion } \\
\text { czas trwania: } 10 \text { min na każde ramię } \\
\text { możliwość zmian wypełnienia fali } \\
\text { intensywnność: 3-10 } \\
\text { 2,4-4,5 W/cm² }\end{array}$ & $\begin{array}{l}\text { ujędrnianie skóry ramion } \\
\text { moc: } 1-84 \mathrm{w} \\
\text { czas trwania: } 20 \mathrm{~min} \\
\text { puls: } 4,0 \mathrm{~Hz} \\
\text { z możliwością: } 0-5,0 \mathrm{~Hz}\end{array}$ \\
\hline Program 5 & $\begin{array}{l}\text { ujędrnianie i wyszczuplanie pośladków } \\
\text { czas trwania: } 15 \text { min } \\
\text { możliwość zmiany wypełnienia fali } \\
\text { intensywnność: 5-10 } \\
\text { 3-4,5 W/cm² }\end{array}$ & $\begin{array}{l}\text { ujędrnianie skóry pośladków } \\
\text { moc: 1-84 W } \\
\text { czas trwania: } 20 \text { min } \\
\text { puls: } 4,0 \mathrm{~Hz} \\
\text { z możliwością: } 0-5,0 \mathrm{~Hz}\end{array}$ \\
\hline Program 6 & $\begin{array}{l}\text { ujędrnianie i wyszczuplanie ud } \\
\text { czas trwania: } 15 \text { min } \\
\text { możliwość zmiany wypełnienia fali } \\
\text { intensywnność: } 5-10 \\
3-4,5 \mathrm{~W} / \mathrm{cm}^{2}\end{array}$ & $\begin{array}{l}\text { ujędrnianie skóry ud } \\
\text { moc: } 1-84 \mathrm{~W} \\
\text { czas trwania: } 20 \mathrm{~min} \\
\text { puls: } 4,0 \mathrm{~Hz} \\
\text { z możliwością: } 0-5,0 \mathrm{~Hz}\end{array}$ \\
\hline
\end{tabular}

W metodzie monopolarnej stosowane są 2 oddzielne elektrody. Elektroda bierna (bez podkładu i preparatu sprzęgającego) umieszczana jest w okolicy krzyżowo-lędźwiowej lub między łopatkami. Za pomocą elektrody czynnej wykonywany jest masaż. W metodzie bipolarnej obie elektrody umieszczone są w aplikatorze (elektrodzie czynnej) w niewielkiej odległości. Intensywniejsze i głębsze oddziaływanie fal radiowych obserwowane jest w metodzie monopolarnej [5]. Przed zabiegiem na powierzchnię skóry aplikowane są specjalne (chłodzące) preparaty kosmetyczne, sprzęgające fale elektromagnetyczne mogące dodatkowo zawierać substancje aktywne o różnych właściwościach (tab. 3).

Podczas oddziaływania fal radiowych zarówno monopolarnych, jak i bipolarnych w skórze właściwej i tkance podskórnej generowane jest ciepło. Tkanki zostają ogrzane do temperatury $45-55^{\circ} \mathrm{C}$. Obecny w skórze właściwej kolagen ulega częściowej denaturacji. Rozerwaniu ulegają niektóre wiązania krzyżowe i dochodzi do rozwinięcia struktury potrójnej helisy, skrócenia i pogrubienia włókien kolagenowych, co wpływa na pojawienie się bezpośrednio po zabiegu efektu liftingu skóry. Częściowa denaturacja kolagenu indukuje złożony proces naprawczy, wynikiem którego jest remodeling skóry właściwej trwający od kilku tygodni do kilku miesięcy. Fale radiowe mogą być stosowane podczas zabiegów odmładzania (ujędrniania) skóry twarzy, powiek, powłok brzusznych, pośladków, skóry ramion oraz modelowania sylwetki [12, 13, $14,15]$. Efekt działania fal radiowych uzależniony jest od metodyki zabiegu, wiedzy i doświadczenia kosmetologa, wieku pacjenta, braku ewentualnych powikłań, które uzależnione 
TABELA 3. Wybrane preparaty stosowane podczas zabiegów z zastosowaniem fal radiowych (na podstawie materiatów informacyjnych producenta)

\begin{tabular}{|c|c|c|}
\hline Producent & Rodzaj & Skład \\
\hline Hebe & $\begin{array}{l}\text { żel sprzęgający fale } \\
\text { elektromagnetyczne }\end{array}$ & lawenda \\
\hline Żelpol & $\begin{array}{l}\text { żel smooth do zabiegów RF } \\
\text { i innych z użyciem prądu } \\
500 \mathrm{~mL}\end{array}$ & $\begin{array}{l}\text { wykonany na bazie wodnej kwas poliglutaminowowy (PGA) nawilża, zwiększa przewodnictwo } \\
\text { oraz likwiduje barierę skóry, zwiększając jej przenikalność na czas zabiegu; skleroglucan } \\
\text { zapewnia ochronę skóry i łagodzenie podrażnień; mocznik wraz trimetylogliceryną ograniczają } \\
\text { transepidermalną utratę wody; bezbarwny }\end{array}$ \\
\hline Clarena & $\begin{array}{l}\text { Ice RF gel } \\
500 \mathrm{~mL}\end{array}$ & kompleks Sepicalm ${ }^{\circledR}$ VG - łagodzi, koi i chłodzi skórę; ekstrakt z babki lancetowatej \\
\hline Isol & $\begin{array}{l}\text { emulsja przeciwstarzeniowa } \\
\text { do RF i elektrostymulacji } \\
250 \mathrm{~mL}\end{array}$ & $\begin{array}{l}\text { echinacea - przyspiesza gojenie ran, ujędrnia; działanie odświeżające i antyseptyczne; żeń-szeń - } \\
\text { właściwości rewitalizujące i odżywcze. Wyciąg z dziurawca - działanie stymulujące i odżywcze; } \\
\text { morski kolagen - działanie ujędrniające, kojące, ściągające i stymulujące mikrokrążenie }\end{array}$ \\
\hline Coel & $\begin{array}{l}\text { hydrożel do EKG i USG } \\
500 \mathrm{~mL}\end{array}$ & $\begin{array}{l}\text { woda oczyszczona, 1,2-propanodiol, polimer kwasu akrylowego, wodorotlenek sodu, } \\
\text { nipoagina m, bronopol, disodu wersenian 2-hydrat }\end{array}$ \\
\hline
\end{tabular}

są od przestrzegania przeciwwskazań do zabiegu i zaleceń producenta urządzenia [16]. Cykl zabiegowy powinien obejmować 4-6 zabiegów wykonywanych w odstępach 2-tygodniowych oraz zabiegu podtrzymującego efekt - przeprowadzanego co pół roku w przypadku skóry twarzy. Natomiast w obrębie innych powierzchni ciała cykl zabiegowy powinien obejmować 5-10 zabiegów przeprowadzanych w odstępach jednego tygodnia. W celu podtrzymania efektu należy stosować 1 zabieg co 1-3 miesiące [11]. Przeciwwskazaniami do przeprowadzenia zabiegu z zastosowaniem prądu i fal radiowych są: choroby zakaźne, infekcje wirusowe, grzybicze i bakteryjne skóry, epilepsja, stwardnienie rozsiane, zaburzenia krążenia obwodowego, zakrzepica, metalowe implanty, pompy infuzyjne, niewyrównana cukrzyca, choroby układu sercowo-naczyniowego, nowotwory, powiększone węzły chłonne, miażdżyca tętnic, zaawansowana osteoporoza, zaburzenia czucia, przerwanie ciągłości skóry [17].

Współczesna kosmetologia oparta jest na różnych osiągnięciach nauk - medycyny, fizyki, chemii, co przyczynia się do efektywnego poszukiwania i wdrażania skutecznej metodyki zabiegów. Coraz częściej preferowane jest łączenie technik zabiegowych z wykorzystaniem różnych bodźców fizykalnych oraz substancji aktywnych. Opracowanie optymalnej metodyki zabiegów kosmetycznych z zastosowaniem elektrostymulacji oraz metodyki zabiegów z zastosowaniem fal elektromagnetycznych o częstotliwości radiowej oraz substancji aktywnych stymulujących regenerację kolagenu, elastyny i kwasu hialuronowego może w istotny sposób poprawić strukturę i parametry skóry, wpływając korzystnie na efekt jej odmłodzenia.

\section{PIŚMIENNICTWO}

1. Leźnicki M. Medykalizacja kobiecego ciała na przykładzie operacji plastycznych. Scienta et Fides 2013;1(1):213-30. doi: 10.12775/SetF.2013.008.
2. Stradowski J. Terapia plastyczna. Wprost 2017. www.wprost.pl (23.01.2017).

3. Mieczkowski M. Prof. Chmaj: medycyna estetyczna z luką prawną. Rynek Estetyczny 2016. http://www.rynekestetyczny.pl/prof-chmaj-medycyna-estetyczna-z-luka-prawna/ (23.01.2017).

4. Glinka M. Krajowa Izba Kosmetologii - jaka jest jej rola? Beauty Project Magazine 2016;wrzesień:5-7. www.beauty-magazine.com.pl/wp-content/ uploads/2016/10/magazyn_publikacja.pdf (23.01.2017).

5. Kasprzak W, Mańkowska A. Fizjoterapia w kosmetologii i medycynie estetycznej. $1^{\text {st }}$ ed. Warszawa: PZWL; 2001.

6. Goodarzi B, Kumar MCh, Darabian A. Comparative effect of electrical muscle stimulation and resistance training on body weight and WHR in overweight people. European Academic Reserch 2014;1(11):4160-75. http://eprints.uni-mysore.ac.in/16851/ (23.01.2017).

7. Parry SM, Berney S, Granger CL, Koopman R, El-Ansary D, Denehy L. Electrical muscle stimulation in the intensive care setting: a systematic review. Crit Care Med 2013;41(10):2406-18.

8. Pisula-Lewandowska A, Mandryn E, Jachowska E, Lewandowski Z. Wpływ elektrostymulacji na zmiany obwodu ud i talii oraz spadek wskaźnika masy ciała u kobiet. Kosmetologia Estetyczna 2014;3(2):131-3.

9. Kurek-Górecka A, Rakoczy B. Metody zwiększania transportu przeznaskórkowego substancji biologicznie aktywnych zawartych w kosmeceutykach. Derm Estet 2013;5-6:324-7.

10. Kamm A. Sezonowe menu zabiegowe - aparatura na pierwszy plan. Beauty Forum 2016;11:34-7.

11. Wnuk I, Bieńkowska M. Radiofrekwencja - energia odmładzająca skórę. CX News 2010;4(34). http://www.cxnews.pl/radiofrekwencja-energia-odnawiajaca-skore,300.html (6.01.2017).

12. Kędzielak-Manikowska I. Odmładzające ciepło Accent Ultra. CX News 2012;4(42). http://www.cxnews.pl/odmladzajace-cieplo-accent-ultra,478. html (6.01.2017).

13. Boisnic S, Branchet MC. Ex-vivo study of hybrid energy technology using a human skin model. Eur J Dermatol 2014;24(1):46-52. doi: 10.1684/ ejd.2013.2233.

14. Fijałkowska M, Gałązka A, Antoszewski B. Ocena skuteczności zabiegów z wykorzystaniem fal radiowych. Pol J Cosmetol 2014;3:257-60.

15. Augustyniak A, Rotsztejn H. Metody odmładzania skóry powiek i okolicy oczu stosowane w kosmetologii i dermatologii estetycznej. Dermatol Estet 2014;16(4-5):244-8.

16. Szwedo J. Analiza powikłań po zabiegach z użyciem fal elektromagnetycznych o wysokiej częstotliwości (RF) na podstawie literatury i doświadczeń własnych. Dermatol Estet 2010;4(69):238-42.

17. Straburzyńska-Lupa A, Straburzyński G. Fizjoterapia z elementami klinicznymi. Warszawa: Wyd. PZWL; 2008. p. 391-412. 